\title{
The overall diet quality in childhood is prospectively associated with the timing of puberty
}

\author{
Ruonan Duan ${ }^{1} \cdot$ Tian Qiao $^{1} \cdot$ Yue Chen ${ }^{1} \cdot$ Mengxue Chen ${ }^{1} \cdot$ Hongmei Xue ${ }^{1,2} \cdot$ Xue Zhou $^{1,3,4} \cdot$ Mingzhe Yang $^{1,5}$.

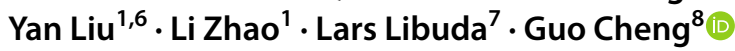

Received: 17 May 2020 / Accepted: 19 October 2020 / Published online: 2 November 2020

(c) The Author(s) 2020

\begin{abstract}
Purpose The influences of nutrition in childhood on puberty onset could have sustained consequences for health and wellbeing later in life. The aim of this study was to investigate the prospective association of diet quality prior to puberty with the timing of puberty onset.

Methods We considered data from 3983 SCCNG (Southwest China Childhood Nutrition and Growth) study participants with dietary data, anthropometric measurement, and information on potential confounders at their baseline assessment (mean age: 7.1 years for girls and 7.3 years for boys; mean length of follow-up was 4.2 years). Cox proportional hazard regression estimating hazard ratios (HRs) and 95\% confidence intervals (CIs) were used to examine the relationship between diet quality and puberty onset. Dietary intake at baseline was assessed using a validated food frequency questionnaire. Diet quality was determined using the Chinese Children Dietary Index (CCDI) which measures adherence to current dietary recommendations (theoretical range: 0-160 points). Age at Tanner stage 2 for breast/genital development (B2/G2), menarche or voice break (M/VB) were used as pubertal markers.

Results The CCDI score ranged from 56.2 to 136.3 for girls and 46.1-131.5 for boys. Pubertal markers consistently indicate that girls and boys with higher diet quality were more likely to enter their puberty later than their counterparts with lower CCDI scores (higher vs. lower CCDI tertiles: adjusted HR for age at B2: 0.85 (95\% CI, 0.81-0.94), $p$ for trend $=0.02$; $\mathrm{G} 2$ : 0.86 (95\% CI,0.80-0.96), $p$ for trend=0.02; M: 0.86 (95\% CI,0.80-0.95), $p$ for trend=0.02; VB: 0.86 (95\% CI,0.79-0.98), $p$ for trend $=0.03$ ), after adjustment for paternal education level, baseline energy intake, and pre-pubertal body fat.

Conclusions Our data suggested a later puberty onset and later timing of progressed puberty stages in children with a high diet quality, which were independent of pre-pubertal body fat.
\end{abstract}

Keywords Diet quality $\cdot$ Puberty timing $\cdot$ Body composition $\cdot$ Children

\section{Introduction}

Age of puberty onset is considered to be of general public health relevance. An early age at puberty onset may be an intermediary factor on the life-course path to a number of hormone-related cancers (breast [1], ovarian [2], endometrial [3], prostate [4, 5] and testicular cancer [6]), allcause mortality [7], and has also been linked to later insulin

Electronic supplementary material The online version of this article (https://doi.org/10.1007/s00394-020-02425-8) contains supplementary material, which is available to authorized users.

Guo Cheng

ehw_cheng@126.com

Extended author information available on the last page of the article resistance [8] and adiposity [9]. In this context, factors influencing puberty timing are increasingly acknowledged.

To date, the influence of modifiable risk factors such as nutrition on puberty onset has been addressed: some [10-12], but not all [13-15] prospective observational studies suggested a role for dietary intakes of nutrients or food groups during pre-puberty: higher energy intake [16] and intakes of animal protein [10, 12], milk [17, 18], red meat [11], and sweetened soft drinks [19, 20] were associated with earlier menarche, whereas higher intakes of total protein [21], carbohydrate [16], fiber [22], isoflavones [23], or yogurt [24] were related to later menarche. However, most of these studies [10-15, 17-24] were focused solely on a single pubertal marker. The use of different pubertal markers covering the range from earlier [pubertal stage 2 for 
breast in girls/genital development in boys (B2/G2)] to later stages [menarche in girls or voice break in boys (M/VB)] of pubertal development might help to elucidate potential mechanisms involved. Moreover, most of the above studies [10-15, 17-24] were conducted in Western countries. In recent years, a secular trend of earlier puberty onset has been observed in both Chinese boys [25] and girls [26]. Few studies have been addressed the influence of dietary factors on puberty timing among Chinese children.

In addition, previous studies considered only single or a few nutrients or foods. It is conceivable that nutrients, food groups, and/or eating behaviours may interact or have additive effects on puberty onset which might be best described when total diet quality is assessed. Dietary indices [27], which measure the extent to which current dietary recommendations are met, can thus provide additional insight into the effect of diet as a whole. To date, two prospective observational studies suggested that US girls with higher adherence to Mediterranean-like diet [28] as well as German children with higher overall diet quality according to German dietary recommendation [29] reached their puberty onset later. To date, one dietary index [30] has been developed for Chinese children, Chinese Children Dietary Index (CCDI), which measures adherence to current dietary recommendations [31] and could, thus, be used to analyze associations between pre-pubertal diet quality and timing of puberty in Chinese children.

The current obesity epidemic has received special attention since body composition in childhood may potentially influence the timing of puberty [32]. In recent years, the prevalence of childhood obesity has risen alarmingly in China [33]. Hence, it is important to examine whether a potential impact of the overall diet quality on the puberty timing is affected by pre-pubertal body composition.

Using prospectively collected data from the Southwest China Childhood Nutrition and Growth (SCCNG) Study, we thus investigated whether the extent to which current dietary recommendations are met in the years preceding puberty onset was associated with the timing of early (B2/ G2) and late (M/VB) pubertal markers. Furthermore, we tested whether this association was affected by pre-pubertal body composition.

\section{Subjects and methods}

\section{Study sample}

The recruitment of SCCNG study participants started in March 2013 in Sichuan Province, Guizhou Province and Chongqing Municipality, which are located in Southwest China. Details on the subject selection procedure and the study protocol have been described elsewhere [34]. In brief, for the yearly recruitment from 2013 onwards eligible participants were children aged 6-8 years in 23 selected primary schools who are cooperative and voluntary at the time of recruitment. At the first examination, information on sociodemographic issues, dietary intake and eating behaviours, physical activity and sedentary behaviours, anthropometry and pubertal development is obtained. From then on, detailed data on nutrition, growth, metabolism, and health status are collected at regular intervals until the age of 15 : the assessments of anthropometry and puberty status are conducted every year, while data of dietary intake and physical activity are collected biennially. The study was approved by the Ethics Committee of the Sichuan University, and all examinations and questionnaires were performed with parental consent.

Between January 2013 and December 2018, 6967 children aged 6-8 years were included for baseline. Of these, 4537 children had completed at least 2 follow-up assessments by the end of 2019. Since we were interested in the prospective relevance of diet quality on puberty timing, 355 children who had already reached B2/G2 at baseline were excluded. 102 participants with implausible energy intakes at baseline according to the age- and sex-specific cut-offs [35] and 97 participants with incomplete information on potential confounders were further excluded. Finally, 3983 children (1752 girls and 2231 boys) were eligible for the present analysis (Fig. 1).

\section{Nutrition assessment and eating behaviors}

The present analyses based primarily on the nutrition data collected via a validated food frequency questionnaire (FFQ) [36] for the consumption of foods and food groups over the past year. Trained investigators collected the information on dietary intake of children from their caregivers in the faceto-face interview. The FFQ included 53 foods or food groups that were most representative of local consumption grouped into 17 categories (whole grains, refined grains, tubers, vegetables, fruits, nuts, meat, fish and shrimp, animal viscera, eggs, dairy and dairy products, soybeans and its products, fried foods, sugary snacks, sugar-sweetened beverages, fruit juice and dietary supplements). Parents were asked to report their children's frequency (never, daily, weekly, monthly and annually) for each food item and the estimated portion size. To increase accuracy in portion size estimation, food models and picture aids were provided. During the interview, the investigators checked FFQs for potentially incorrect responses and clarified with participants' caregivers when necessary. Dietary intake data are converted into energy and nutrient intake data using the continuously updated in-house nutrient database based on NCCW software (version 11.0, 2014), which reflects the China Food Composition. 
Fig. 1 Flowchart for the study sample
4537 children

with bascline dictary information and at least two follow-up assessments

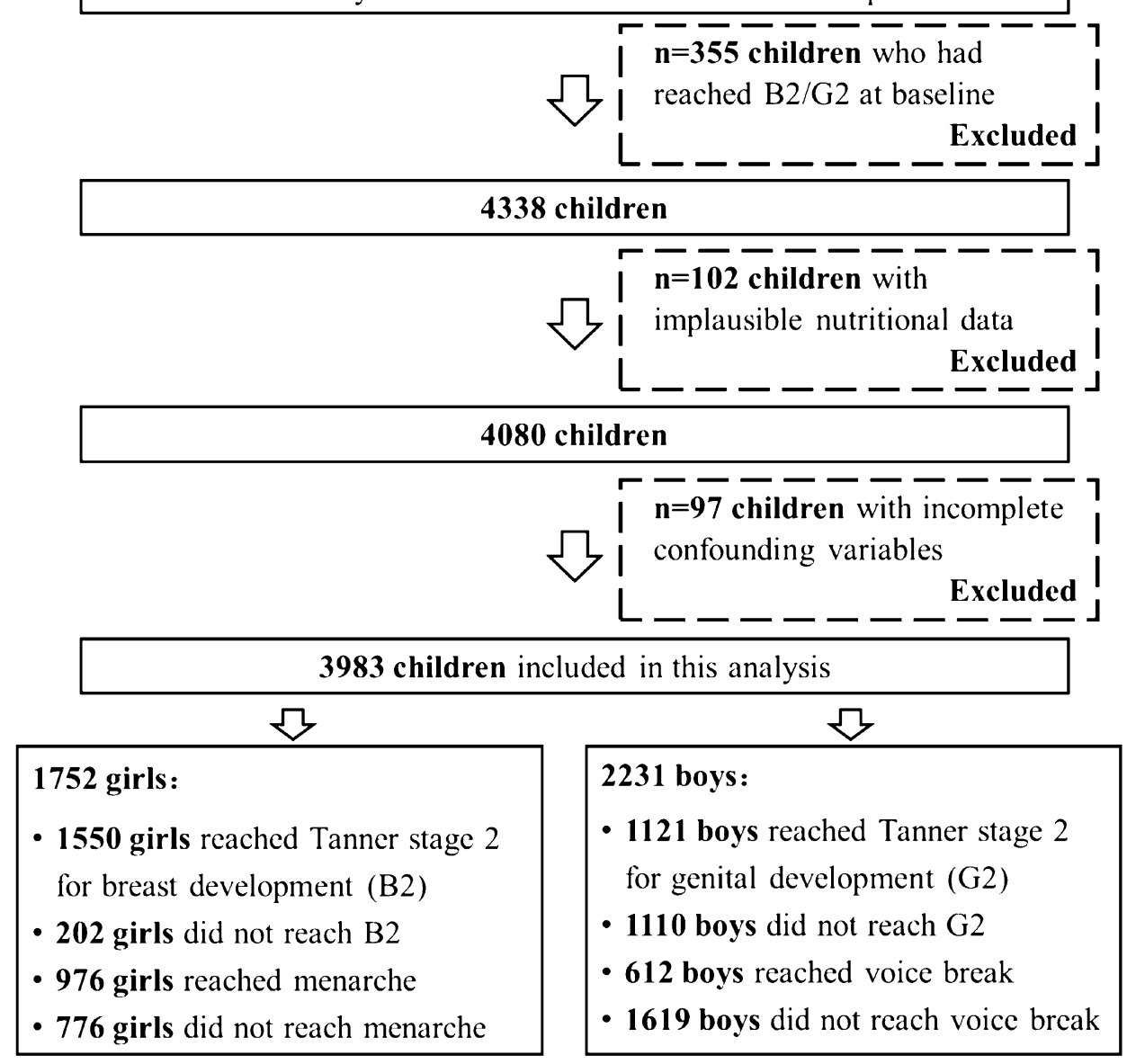

In addition, 3-day $24-\mathrm{h}$ recalls were used in the SCCNG to collect dietary intake data by trained investigators. For children younger than 9 years, their caregivers provided the information on food consumption at home, while children provided the dietary intake information from school themselves. Details on recipes and brands of all food items reported were inquired. Food models, standard tableware including bowls, plates and glasses were provided to improve the accuracy of the portionsize estimates. In addition, children were given a photo book, which contains photos of snacks and beverages and the pictures of the commonly used commercial packaging (e.g., one carton) to improve the diet recall. For this study, dietary intake data from 24-h recalls was used in our sensitivity analysis.

For eating behaviors relevant to diet quality of children, participants were asked whether they often ate breakfast (at least 5 days per week) or had dinner with parents/grandparents regularly (at least 5 days per week).

\section{Measurement of dietary quality}

The Chinese Children Dietary Index (CCDI) [30] was initially developed to rate diet quality in children by scoring their nutritional intakes in relation to the Chinese dietary intake recommendations (Chinese Dietary Guidelines 2007 [37] and Chinese Dietary Reference Intakes 2013 [38]) and addressing health-promoting behaviours. Modified CCDI, which measures adherence to current Chinese dietary recommendation, was used in the present analysis. The modified CCDI was based on the Chinese Dietary Guidelines 2016 [31], which provided specific dietary intake recommendations for children aged 7-10 years, 11-13 years, and 14-17 years, respectively. The development of modified CCDI and its calculation are described in detail elsewhere [39]. Briefly, the CCDI incorporated 16 components, including grains, vegetables, fruits, dairy and dairy products, soybeans and its products, meat, fish and shrimp, eggs, drinking water, sugar-sweetened beverages, vitamin A, fatty acids, fiber, 
dietary variety, eat breakfast or have dinner with parents/ grandparents regularly, and energy balance. Each component in CCDI contributed 0-10 points to the total score and children who consumed appropriate types and amounts of foods or nutrients and engaged in health-promoting behaviors received full points for each component. Therefore, the range of CCDI score is $0-160$, with a higher score indicating a better diet quality.

\section{Assessment of puberty onset}

In the SCCNG study, pubertal maturation for breast (girls) and pubic hair (girls and boys) stages were assessed at each examination by investigators according to the standardized criteria of Tanner stages [40]. Testicular volume was assessed by comparative palpation with the Prader orchidometer. If the testicular volumes of the two testes were not equal, the volume of the larger one was recorded. Testicular volume less than $1 \mathrm{~mL}$ was recorded as $1 \mathrm{~mL}$. In addition, during the annual physical examination for children, children were asked whether menarche (girls) or voice break (boys) had already occurred and the respective month and year were recorded.

For this analysis, age at Tanner stage 2 for breast development in girls and the initiation of gonadal growth in boys as well as age at menarche in girls and age at voice break in boys, respectively, were considered.

\section{Anthropometry}

An Ultrasonic Weight and Height Instrument (DHM-30, Dingheng Ltd, Zhengzhou, China) was used to assess standing height to the nearest $0.1 \mathrm{~cm}$ and weight to the nearest $0.1 \mathrm{~kg}$ with the subjects dressed lightly and barefoot. Additionally, skinfold thicknesses of triceps and subscapular angle sites were measured on the right side of the body to the nearest $0.1 \mathrm{~mm}$ using a Holtain caliper (Holtain Ltd, Crymych, UK). All anthropometric measurements were performed twice and the averages were calculated for each child.

For body mass index (BMI) sex- and age-independent BMI SDS were calculated using the Chinese reference curves [41]. Overweight was defined according to the International Obesity Task Force (IOTF) BMI cut-offs for children, which correspond to an adult BMI of $25 \mathrm{~kg} / \mathrm{m}^{2}$ [42]. Percent body fat (\%BF) was calculated using the Slaughter equations [43].

\section{Covariates}

Parents were asked to provide information about pregnancy and infancy (i.e., children's birth weight, exclusive breastfeeding duration, timing of complementary feeding), and family characteristics (i.e., place of residence, household income, family size, smoking in the household, parental age, parental occupation and education levels).

A validated physical activity questionnaire (PAQ) was used to collect information on the frequency, duration and type of physical activity inside and outside school settings as well as leisure-time activities. The PAQ included a checklist of 38 items, i.e., walking, running, climbing stairs, ball games, dancing and so on. In addition, participants were asked to report the usual time spent on sedentary behaviours, i.e., watching television, using computers, using smart phones and doing homework) on weekdays and on weekends.

\section{Statistical analysis}

SAS $^{\circledR}$ procedures (version 9.4, SAS Inc, Cary, NC) were used for all data analyses. All analyses were performed with significance level at $p<0.05$.

To obtain three categories characterizing a lower, moderate and higher diet quality, the continuous CCDI scores were divided into three groups based on the sex-specific tertiles. Kolmogorov-Smirnov and Shapiro-Wilk tests were conducted to test the normality of the data. Birth weight and percent body fatness at baseline were not normally distributed and presented as medians (25th percentile, 75 th percentile), while other continuous variables were normally distributed and presented as means (SD). Differences in anthropometric data, socio-demographic data and nutritional intake between groups of CCDI were tested using ANOVA test for normally distributed continuous variables, Kruskal-Wallis test for not normally distributed continuous variables, followed by Student-Newman-Keuls tests or Dunn's post hoc tests. Chi square test was used for categorical variables. Since different pubertal markers were used in boys and girls, statistical models as well as descriptive tables were stratified by sex.

To investigate the prospective relevance of diet quality at baseline according to CCDI with age at B2/G2 and M/ $\mathrm{VB}, \mathrm{Cox}$ proportional hazard regression models were used. Censoring occurred at the age of reaching B2/G2, M/VB or age at last follow-up assessment if the respective pubertal stage had not been achieved. In the basic models, the tertiles of CCDI score at baseline were the principle independent fixed effects. Cox regression models considered birth weight, age at baseline, physical activity, family income, paternal/maternal educational level, smoking in the household, and total energy intake at baseline as potential confounders. Each potential confounder was initially considered separately and included if it was associated with both the dietary index and indicators of puberty timing and substantially altered the estimate by more than $10 \%$ in both girls and boys. Thus, paternal education level and energy intake at baseline were adjusted for in model 2. In a final model, 
percent body fatness at baseline was additionally included because it has been proposed that childhood body composition might be related to puberty timing [44]. Hazard ratios (HRs) and 95\% confidence intervals (CIs) were estimated by comparing the moderate and higher diet quality to the lower diet quality in these models.

To test the robustness of our results, CCDI scores were recalculated using dietary data estimated from three 24-h recalls instead of FFQ data and included in the models.

\section{Results}

In total, 3983 children (1752 girls and 2231 boys) were included in the present analyses. The mean age at baseline was $7.1(0.7)$ years for girls and $7.3(0.8)$ years for boys. They were followed up 4.2 years. Among girls, 1550 $(88.5 \%)$ had reached B2, and $976(55.7 \%)$ had experienced menarche. Among boys, 1121 (50.2\%) had reached G2, and $612(27.4 \%)$ had experienced voice break. There were no significant differences in age at baseline, or the BMI SDS or percentage body fat between these 3983 children and the 102 children who provided pubertal data and anthropometry, but were excluded from this analysis because of missing or implausible nutritional data (data not shown).

In our participants, the CCDI score estimated with the individual mean values of dietary data at baseline ranged from 56.2 to 136.3 for girls and 46.1-131.5 for boys (Table 1). Generally, the diet quality of girls (CCDI score: 90.7 (15.5)) was higher than that of boys (CCDI score: 87.9 (14.9)) $(p<0.0001)$. Boys and girls with a higher diet quality according to the CCDI were more likely to have a higher educated father and to live in a household with less smoking compared to their counterparts with lower diet quality. Girls with a higher diet quality consumed significantly more carbohydrates and less protein and fat, while boys with a higher diet quality consumed significantly more carbohydrate and less protein. Despite the fact that the components of the CCDI partly account for energy intake, a higher diet quality tended to be associated with a lower energy intake $(p=0.06)$. In both genders, a higher diet quality was associated with a lower \%BF, a later age at Tanner stage B2 and menarche for girls and a later age at voice break for boys as compared to their counterparts with a lower diet quality.

The dietary intake of each component of CCDI estimated with individual mean values of dietary data at baseline and sub-scores of CCDI are presented in Table 2. Among girls, the highest median sub-scores, i.e., adherence to dietary recommendations, were observed for fatty acids, breakfast and dinner, energy balance component, and dairy and dairy products (10.0 for fatty acids, 9.0 for breakfast and dinner, 8.3 for energy balance, 8.0 for dairy and dairy products). However, scores for eggs and fish and shrimp were much lower ( $\leq 3$ points), reflecting excessive meat consumption and inadequate consumption of fish, shrimp and eggs. More than $60 \%$ of our girls consumed vegetables and fruits below the recommendations issued by Chinese Dietary Guidelines resulting in low mean sub-scores especially for vegetables (4.6) and also for dietary fiber (3.9).

Among boys, the overall distribution of the CCDI components was comparable, with high mean sub-scores observed for fatty acids and dairy and dairy products, and low scores for fish and shrimp, and meat. In contrast to girls, the subscore for grains was lower than 3 points, reflecting a diet with excessive grain and meat consumption and inadequate consumption of fish and shrimps in boys. More than $75 \%$ of our boys consumed vegetables and soybeans and its products below the recommendations issued by Chinese Dietary Guidelines; the mean sub-scores for vegetables, soybeans and its products and dietary fiber were 4.5, 3.8 and 3.6, respectively. Similar distributions of each component of CCDI in girls and boys were found when using dietary values estimated from 24-h recalls (Table S1).

Cox proportional hazard regression models revealed positive associations of diet quality at baseline with early and late markers of puberty (Table 3 ) in both genders, which remained significant when the potential confounder body fat at baseline was included in the final model. According to the final models, girls with a higher diet quality were more likely to reach their B2 [adjusted HR: 0.85 (95\% CI, 0.81-0.94), $p$ for trend $=0.02$ ] and menarche [adjusted HR: $0.86(95 \%$ CI, 0.80-0.95), $p$ for trend $=0.02$ ] later than girls with a lower diet quality. Similarly, boys with a higher diet quality were more likely to experience their G2 [adjusted HR: 0.86 (95\% CI, 0.80-0.96), $p$ for trend $=0.02$ ] and VB [adjusted HR:0.86 (95\% CI, 0.79-0.98), $p$ for trend $=0.03$ ] than boys with a lower diet quality at a later age.

Our results were similar in sensitivity analyses. When we used dietary values estimated from 24-h recalls to examine associations between diet quality at baseline and puberty timing, relation estimates were similar (Table S2).

\section{Discussion}

Our study suggests that both girls and boys who had a higher diet quality in pre-puberty, as indicated by the CCDI, experienced their puberty timing at a later age than children with a lower diet quality. This association was observed independently of their pre-pubertal body fat.

Puberty onset is a milestone of growth for both boys and girls. An earlier puberty onset could represent one of the immediate health outcomes associated with diet quality in childhood. In 2010, data from 222 Dortmund Nutritional and Anthropometric Longitudinally Designed (DONALD) study participants showed that children with higher diet quality 
Table 1 Characteristics of participants by group of diet quality at baseline

\begin{tabular}{|c|c|c|c|c|}
\hline & \multicolumn{3}{|c|}{ Diet quality according to CCDI score } & \multirow[t]{2}{*}{$p$} \\
\hline & Lower $(56.2-82.3)^{\mathrm{b}}$ & Moderate $(82.9-105.6)^{\mathrm{b}}$ & Higher $(106.2-136.3)^{b}$ & \\
\hline \multicolumn{5}{|l|}{ Girls $(n=1752)$} \\
\hline$N(\%)$ & $584(33.3)$ & $584(33.3)$ & $584(33.3)$ & \\
\hline Birth weight (kg) & $3.1(2.8,3.8)$ & $3.3(2.9,3.7)$ & $3.2(2.7,3.8)$ & 0.3 \\
\hline Age at baseline (years) & $7.1(0.8)$ & $7.3(0.8)$ & $7.2(0.9)$ & 0.1 \\
\hline Age at menarche (years, $n=976$ ) & $12.6(0.8)$ & $12.8(0.9)^{*}$ & $13.2(1.0) \# ※$ & 0.02 \\
\hline Age at Tanner stage $\mathrm{B} 2^{\mathrm{d}}$ (years, $n=1550$ ) & $9.0(1.4)$ & $9.3(1.5)^{*}$ & $9.6(1.2) \# ※$ & 0.01 \\
\hline BMI SDS at baseline $\left(\mathrm{kg} / \mathrm{m}^{2}\right)$ & $0.3(0.8)$ & $0.2(0.7)$ & $0.2(0.8)$ & 0.1 \\
\hline Percent body fatness ${ }^{\mathrm{e}}$ at baseline (\%) & $16.9(15.3,19.6)$ & $16.5(15.1,18.4)^{*}$ & $15.7(13.6,18.8) \# ※$ & 0.04 \\
\hline Overweight $^{\mathrm{f}}(n(\%))$ & $77(13.2)$ & $66(11.3)$ & $64(11.0)$ & 0.1 \\
\hline High physical activity $(n(\%))$ & $153(26.2)$ & $168(28.8)$ & $166(28.4)$ & 0.06 \\
\hline Duration of breastfeeding (weeks) & $16.8(5.9)$ & $15.7(5.3)$ & $18.6(6.3)$ & 0.07 \\
\hline \multicolumn{5}{|l|}{ Parental data at baseline } \\
\hline High family income ${ }^{\mathrm{g}}(n(\%))$ & $122(20.8)$ & $130(22.3)$ & $137(23.5)$ & 0.06 \\
\hline High paternal educational level ${ }^{\mathrm{h}}(n(\%))$ & $117(20.0)$ & $137(23.5)^{*}$ & 151 (25.9)\#※ & 0.04 \\
\hline High maternal educational level ${ }^{\mathrm{h}}(n(\%))$ & $105(18.0)$ & $108(18.5)$ & $111(19.0)$ & 0.07 \\
\hline Smoking in the household $(n(\%))$ & $386(66.1)$ & $328(56.2)^{*}$ & 284 (48.6)\#※ & 0.02 \\
\hline Mother's age at menarche (years) & $12.0(0.9)$ & $12.3(0.8)^{*}$ & 12.5 (1.1)\#※ & 0.05 \\
\hline \multicolumn{5}{|l|}{ Nutritional data ${ }^{\mathrm{i}}$} \\
\hline Total energy intake (kcal/d) & $1401(228)$ & $1626(237)$ & $1531(232)$ & 0.06 \\
\hline Carbohydrates (\% of energy) & $53.1(5.2)$ & $58.8(4.3)^{*}$ & $57.3(4.5) \# ※$ & 0.04 \\
\hline Fat (\% of energy) & $32.3(4.9)$ & $26.1(4.3)^{*}$ & $29.0(4.4) \# ※$ & 0.02 \\
\hline \multirow[t]{2}{*}{ Protein (\% of energy) } & $14.6(2.2)$ & $15.1(2.1)^{*}$ & $13.7(1.9) \# ※$ & 0.03 \\
\hline & Lower $(46.1-77.5)^{\mathrm{j}}$ & Moderate $(78.2-101.7)^{\mathrm{j}}$ & Higher $(102.3-131.5)^{\mathrm{j}}$ & $p$ \\
\hline \multicolumn{5}{|l|}{ Boys } \\
\hline$N(\%)$ & $743(33.3)$ & $744(33.3)$ & $744(33.3)$ & \\
\hline Birth weight (kg) & $3.6(3.1,3.9)$ & $3.3(2.8,4.1)$ & $3.4(2.8,3.9)$ & 0.1 \\
\hline Age at baseline (years) & $7.0(0.9)$ & $7.3(0.7)$ & $7.1(0.8)$ & 0.1 \\
\hline Age at voice break (years, $n=612$ ) & $13.5(1.2)$ & $13.8(1.3)^{*}$ & 14.1 (1.1)\#※ & 0.03 \\
\hline Age at pubertal stage $\mathrm{G} 2^{\mathrm{d}}$ (years, $n=1121$ ) & $10.9(1.2)$ & $11.2(1.4)$ & $11.4(1.0)$ & 0.05 \\
\hline BMI SDS at baseline $\left(\mathrm{kg} / \mathrm{m}^{2}\right)$ & $0.3(0.8)$ & $0.3(0.6)$ & $0.2(0.7)$ & 0.3 \\
\hline Percent body fatness ${ }^{\mathrm{e}}$ at baseline (\%) & $13.9(11.4,17.5)$ & $13.6(10.2,17.3)^{*}$ & $13.5(11.0,17.8) \# ※$ & 0.04 \\
\hline Overweight ${ }^{\mathrm{f}}$ at baseline $(n(\%))$ & $104(14.0)$ & $89(12.0)$ & $83(11.2)$ & 0.09 \\
\hline High physical activity $(n(\%))$ & $197(26.5)$ & $219(29.4)$ & $215(28.9)$ & 0.06 \\
\hline Duration of breastfeeding (weeks) & $19.2(5.2)$ & $20.5(5.8)$ & $20.6(6.1)$ & 0.08 \\
\hline \multicolumn{5}{|l|}{ Parental data at baseline } \\
\hline High family income ${ }^{g}(n(\%))$ & $152(20.5)$ & $153(20.6)$ & $158(21.2)$ & 0.07 \\
\hline High paternal educational level ${ }^{\mathrm{h}}(n(\%))$ & $166(22.3)$ & $176(23.6)^{*}$ & 187 (25.1)\#※ & 0.03 \\
\hline High maternal educational level ${ }^{\mathrm{h}}(n(\%))$ & $135(18.2)$ & $136(18.3)$ & $141(19.0)$ & 0.05 \\
\hline Smoking in the household $(n(\%))$ & $499(67.2)$ & $425(57.1)^{*}$ & 391 (52.6)\#※ & 0.03 \\
\hline Mother's age at menarche (years) & $12.2(0.7)$ & $12.4(0.9)$ & $12.3(0.8)$ & 0.08 \\
\hline \multicolumn{5}{|l|}{ Nutritional data ${ }^{\mathrm{i}}$} \\
\hline Total energy intake (kcal/d) & $1910(237)$ & $1816(218)$ & $1772(223)$ & 0.06 \\
\hline Carbohydrates ( $\%$ of energy) & $58.7(6.5)$ & $59.8(6.2)^{*}$ & $61.0(5.8) \# ※$ & 0.03 \\
\hline Fat (\% of energy) & $26.4(4.6)$ & $27.3(4.2)$ & $26.5(4.4)$ & 0.05 \\
\hline Protein (\% of energy) & $14.9(2.4)$ & $12.9(2.2)^{*}$ & 12.5 (2.0)\#※ & 0.04 \\
\hline
\end{tabular}

${ }^{\mathrm{a}}$ Values are means (SD), medians (Q1, Q3) or frequency; CCDI, Chinese Children Dietary Index, based on dietary data at baseline

${ }^{\mathrm{b}}$ Values are min-max in tertiles in girls

${ }^{\mathrm{c}}$ Test for difference between the groups was performed, using ANOVA test for normally distributed continuous variables, Kruskal-Wallis test for 
Table 1 (continued)

not normally distributed continuous variables, followed by Student-Newman-Keuls tests or Dunn's post hoc tests, and Chi square test for categorical variables. $* P<0.05$ between lower and moderate diet quality group, $\# P<0.05$ between moderate and higher diet quality group $<0.05$, $※ P<0.05$ between lower and higher diet quality group

${ }^{\mathrm{d}}$ Tanner stage 2 for breast development (girls) or the initiation of gonadal growth (boys)

${ }^{\mathrm{e}}$ Calculated according to Slaughter et al. [43]

${ }^{\mathrm{f}}$ Definition according to the International Obesity Task Force (IOTF) [53]

${ }^{\mathrm{g}}$ Average annual income of family at least $\geq 35,000 \mathrm{CNY}$ (Chinese Yuan), which is moderate level among the general population in South China

${ }^{\mathrm{h}}$ School education at least 12 years

${ }^{\mathrm{i}}$ Mean values of dietary data at baseline using food frequency questionnaires

${ }^{\mathrm{j}}$ Values are min-max in tertiles in boys

entered puberty approximately 0.4 year later than their counterparts with lower diet quality [29]. Based on the working experience of the DONALD Study, we designed the SCCNG with large sample size and detailed assessments of dietary intake as well as frequent follow-ups to investigate the prospective relevance of diet quality on growth development among Chinese children. The difference in early and late puberty markers between children with a lower diet quality and children with a higher diet quality observed in our study may have long-term consequences for risk of cancers including breast [1], ovarian [2], endometrial [3], prostate [4, 5] and testicular cancer [6]. In this analysis, the diet quality was examined at 4.2 years preceding puberty onset, which suggested that the diet quality in childhood may have potentially long-term effects for puberty timing. Moreover, the influence of higher diet quality on later puberty timing was found both in girls and boys in the present study. A meta-analysis of 12 cohort studies with 2,341,769 participants has demonstrated that a one year delay in menarche is associated with a $3.3 \%$ lower all-cause mortality or $4.1 \%$ lower ischemic heart disease mortality [7]. Although such data are only available for menarche, we believe that our finding of $14-15 \%$ lower probability of experiencing puberty timing at earlier age in those with a higher diet quality may thus be of public health relevance. In addition, our results have a more direct public health implication than studies focusing on single nutrients: a closer adherence to current dietary recommendation appears to yield a later puberty onset. In the present study, we could use the dietary index which is currently available specifically for Chinese children. In view of the increasing trend towards earlier puberty onset among Chinese children, public health initiatives should be tailored at improving the quality of dietary intake.

In this study, both boys and girls with a higher diet quality according to CCDI were more likely to have higher intakes of dairy and dairy products, dietary fiber, vegetables, fruits and soybeans, lower intakes of meat and SSB, and having breakfast and dinner more with parents and grandparents. Our findings are thus in line with previous prospective observational studies focusing on single nutrients and food groups, which suggested that higher intakes of fiber [22] or isoflavones [23], or lower meat [11, 12] or SSB [19, 20] consumptions were associated with a later timing of menarche. Previous studies have suggest that diet rich in fiber and isoflavones may delay timing of puberty by increasing sex hormone-binding globulin and decreasing endogenous estrogens [28, 45] among girls. Conversely, intake of SSB may contribute to high levels of insulin secretion and insulin-like growth factor1 (IGF-1), which could result in early onset of puberty $[19,46]$. The robust association in our study may hence reflect a combined effect of these foods and food groups. However, the underlying mechanisms of the impact of dietary intake on boys' puberty timing require further research. Interestingly, additional analyses suggested that the association of the CCDI with the puberty timing was partly driven by eating behaviors: having breakfast and dinner more with parents and grandparents, especially among girls (data not shown). This might suggest that the health promoted eating behaviors may be crucial with respect to puberty timing [47]. Hence, public health initiatives should not be only concentrated in improving the consumption of nutrients or foods/food groups, but also focused on the health promoted eating behaviors or eating environment.

In this study, the association of diet quality with puberty timing was not affected by body composition in pre-puberty, although our children with a lower diet quality seem to have more body fat. Instead, higher fat intakes and lower intakes of vegetables and fiber [48] among those with a lower diet quality may have enhanced the availability of circulating estrogen or be associated with higher leptin concentrations, thereby influencing pubertal development [49]. Thus, the association of diet quality in pre-puberty with the timing of puberty onset is independent of the pre-pubertal body composition, but may have been mediated by estrogen and leptin metabolism.

Our study has several strengths. In contrast to previous studies focused only on girls, this study examined data from both girls and boys. The prospective nature, and repeated detailed measurements of anthropometric, pubertal and dietary data in participants in conjunction with the ability 
Table 2 Dietary intake ${ }^{a}$ by groups of diet quality and the medians (25th percentile, 75 th percentile) of CCDI sub-scores ${ }^{\mathrm{b}}$

\begin{tabular}{|c|c|c|c|c|c|}
\hline & \multicolumn{3}{|c|}{ Diet quality according to CCDI score } & \multirow[t]{2}{*}{ Sub-scores of CCDI } & \multirow{2}{*}{$\begin{array}{l}\text { Percentage of partici- } \\
\text { pants meeting dietary } \\
\text { recommendations }\end{array}$} \\
\hline & Lower $(56.2-82.3)^{\mathrm{c}}$ & $\begin{array}{l}\text { Moderate (82.9- } \\
105.6)^{\mathrm{c}}\end{array}$ & Higher $(106.2-136.3)^{c}$ & & \\
\hline \multicolumn{6}{|l|}{ Girls } \\
\hline Grains, g/d & $487(402,589)$ & $346(263,379)$ & $172(115,263)$ & $5.7(3.3,7.8)$ & $12.6 \%$ \\
\hline Vegetables, g/d & $99(81,123)$ & $159(136,178)$ & $263(252,296)$ & $4.6(2.9,7.4)$ & $16.1 \%$ \\
\hline Fruits, $g / d$ & $41(29,62)$ & $115(97,136)$ & $163(148,207)$ & $7.0(3.6,10.0)$ & $37.8 \%$ \\
\hline $\begin{array}{l}\text { Dairy and dairy } \\
\text { products, g/d }\end{array}$ & $67(54,95)$ & $243(201,252)$ & $294(279,345)$ & $8.0(3.5,10.0)$ & $38.1 \%$ \\
\hline $\begin{array}{l}\text { Soybeans and its } \\
\text { products, g/d }\end{array}$ & $3.6(0,7.1)$ & $13(8.9,17)$ & $57(39,89)$ & $4.5(2.4,10.0)$ & $26.7 \%$ \\
\hline Meats, g/d & $73(11,136)$ & $65(33,102)$ & $41(35,82)$ & $3.3(0,7.1)$ & $14.7 \%$ \\
\hline $\begin{array}{l}\text { Fishes and shrimps, } \\
\text { g/d }\end{array}$ & $0(0,0)$ & $6(3,19)$ & $25(19,38)$ & $0(0,5.1)$ & $9.3 \%$ \\
\hline Eggs, g/d & $0(0,0)$ & $15(10,25)$ & $58(43,86)$ & $2.7(0,8.0)$ & $13.1 \%$ \\
\hline Drinking water, $\mathrm{mL} / \mathrm{d}$ & $350(225,425)$ & $575(500,750)$ & $975(925,1200)$ & $5.0(3.3,8.3)$ & $17.2 \%$ \\
\hline $\mathrm{SSBs}^{\mathrm{d}}, \mathrm{mL} / \mathrm{d}$ & $155(128,201)$ & $78(35,103)$ & $0(0,0)$ & $4.5(2.2,10.0)$ & $26.9 \%$ \\
\hline Vitamin A, $\mu \mathrm{gRE} / \mathrm{d}$ & $181(160,212)$ & $325(293,346)$ & $465(428,492)$ & $5.5(3.2,8.9)$ & $21.2 \%$ \\
\hline Fatty acids ${ }^{\mathrm{e}}$ & $1.6(1.2,2.0)$ & $2.4(2.0,2.9)$ & $3.4(3.0,3.8)$ & $10.0(3.9,10.0)$ & $55.1 \%$ \\
\hline Dietary fiber, g/d & $5.2(4.3,6.5)$ & $8.5(7.2,9.7)$ & $12(9.8,14)$ & $3.9(2.4,4.5)$ & $11.7 \%$ \\
\hline $\begin{array}{l}\text { Diet variety } \\
(\text { servings })^{\mathrm{f}}\end{array}$ & $6(4,9)$ & $9(6,13)$ & $12(9,16)$ & $7.0(4.0,9.0)$ & $21.2 \%$ \\
\hline Breakfast and dinner ${ }^{\mathrm{g}}$ & $5(4,8)$ & $7(5,10)$ & $9(8,11)$ & $9.0(7.0,10.0)$ & $39.1 \%$ \\
\hline \multirow[t]{2}{*}{ Energy balance $^{\mathrm{h}}$} & $0.7(0.4,2.2)$ & $0.9(0.6,1.6)$ & $1.1(0.7,1.3)$ & $8.3(3.5,9.9)$ & $23.9 \%$ \\
\hline & Lower $(46.1-77.5)^{\mathrm{i}}$ & $\begin{array}{l}\text { Moderate (78.2- } \\
101.7)^{\mathrm{i}}\end{array}$ & Higher $(102.3-131.5)^{\mathrm{i}}$ & $\begin{array}{l}\text { Distribution of sub- } \\
\text { scores }\end{array}$ & $\begin{array}{l}\text { Percentage of partici- } \\
\text { pants meeting dietary } \\
\text { recommendations }\end{array}$ \\
\hline \multicolumn{6}{|l|}{ Boys } \\
\hline Grains, g/d & $535(489,553)$ & $447(311,514)$ & $215(162,348)$ & $2.7(0,6.1)$ & $9.1 \%$ \\
\hline Vegetables, g/d & $87(71,112)$ & $145(121,163)$ & $238(218,251)$ & $4.5(2.4,6.9)$ & $11.2 \%$ \\
\hline Fruits, g/d & $26(19,39)$ & $141(112,175)$ & $178(165,213)$ & $6.5(1.2,10.0)$ & $31.6 \%$ \\
\hline $\begin{array}{l}\text { Dairy and dairy } \\
\text { products, } g / d\end{array}$ & $81(69,96)$ & $275(230,319)$ & $348(316,391)$ & $8.6(5.4,10.0)$ & $41.3 \%$ \\
\hline $\begin{array}{l}\text { Soybeans and its } \\
\text { products, g/d }\end{array}$ & $0(0,0)$ & $12(7.4,23)$ & $73(41,102)$ & $3.8(0,10.0)$ & $25.2 \%$ \\
\hline Meats, g/d & $98(65,187)$ & $78(41,127)$ & $46(35,79)$ & $1.2(0,5.9)$ & $8.3 \%$ \\
\hline $\begin{array}{l}\text { Fishes and shrimps, } \\
\text { g/d }\end{array}$ & $0(0,0)$ & $7(2,19)$ & $31(21,45)$ & $0(0,7.0)$ & $7.2 \%$ \\
\hline Eggs, g/d & $0(0,0)$ & $24(16,39)$ & $73(52,105)$ & $3.4(0,10)$ & $25.8 \%$ \\
\hline Drinking water, mL/d & $425(325,475)$ & $650(525,800)$ & $1075(875,1200)$ & $5.7(4.0,8.9)$ & $19.8 \%$ \\
\hline $\mathrm{SSBs}^{\mathrm{d}}, \mathrm{mL} / \mathrm{d}$ & $182(119,237)$ & $85(48,117)$ & $0(0,0)$ & $4.0(2.3,10.0)$ & $25.5 \%$ \\
\hline Vitamin $\mathrm{A}, \mu \mathrm{gRE} / \mathrm{d}$ & $166(151,182)$ & $293(270,338)$ & $442(408,486)$ & $5.1(3.0,8.9)$ & $19.5 \%$ \\
\hline Fatty acids ${ }^{\mathrm{e}}$ & $1.5(1.1,1.8)$ & $2.4(2.0,2.9)$ & $3.7(3.3,3.8)$ & $10.0(5.0,10.0)$ & $58.1 \%$ \\
\hline Dietary fiber, g/d & $4.2(3.1,5.5)$ & $7.3(6.1,8.7)$ & $10(9.0,13)$ & $3.6(2.1,4.5)$ & $9.4 \%$ \\
\hline Diet variety ${ }^{\mathrm{f}}$ & $6(4,9)$ & $8(7,11)$ & $10(8,14)$ & $6.0(4.0,8.0)$ & $19.6 \%$ \\
\hline Breakfast and dinner ${ }^{\mathrm{g}}$ & $6(5,9)$ & $8(6,10)$ & $9(7,11)$ & $8.0(6.0,10.0)$ & $29.1 \%$ \\
\hline Energy balance ${ }^{\mathrm{h}}$ & $1.2(0.5,2.6)$ & $0.8(0.5,1.2)$ & $1.1(0.7,1.3)$ & $8.1(3.0,9.7)$ & $23.0 \%$ \\
\hline
\end{tabular}

${ }^{a}$ All nutritional data represent crude values per day. Mean values of dietary data at baseline

${ }^{\mathrm{b}}$ Data are presented as medians (25th percentile, 75th percentile) in tertiles, $n=3983$. CCDI Chinese Children Dietary Index, based on dietary data at baseline

${ }^{c}$ Values are min-max in tertiles in girls

${ }^{\mathrm{d}}$ SSBs, sugar-sweetened beverages. SSBs were defined as beverages with added sugar, such as lemonades, fruit drinks (diluted and sugar-sweet- 
Table 2 (continued)

ened fruit juices), ice teas and so on. Juices made from 100\% fruit were not classified as SSBs

${ }^{\mathrm{e}}$ Ratio of poly- and monounsaturated fatty acids to saturated fatty acids, derived from the HEI-2010 [54]

${ }^{\mathrm{f}}$ Daily consumption of at least one serving from each of the food groups (grains, vegetables, fruits, dairy/beans and meats/poultry/fishes/eggs) was necessary to count the diet variety

${ }^{g}$ Frequencies per week, having breakfast and dinner with parents or grandparents

${ }^{\text {h}}$ Energy balance was reflected by energy intake and time spent on sedentary behaviors. Energy expenditure was reflected by time spent on sedentary behaviors, i.e., watching television, using computers and doing homework

${ }^{\mathrm{i}}$ Values are min-max in tertiles in boys

Table 3 Association of diet quality in childhood with puberty timing ${ }^{\mathrm{a}}$

\begin{tabular}{|c|c|c|c|c|}
\hline & \multicolumn{3}{|c|}{ Diet quality according to CCDI score } & \multirow[t]{2}{*}{$p_{\text {trend }}{ }^{\mathrm{c}}$} \\
\hline & Lower $(56.2-82.3)^{\mathrm{b}}$ & Moderate $(82.9-105.6)^{\mathrm{b}}$ & Higher $(106.2-136.3)^{b}$ & \\
\hline \multicolumn{5}{|l|}{ Girls } \\
\hline \multicolumn{5}{|c|}{ Age at Tanner stage B2 $(n=1752)$} \\
\hline Unadjusted model: & 1 & $0.90(0.81,0.97)$ & $0.86(0.79,0.93)$ & 0.04 \\
\hline Model 2d: & 1 & $0.88(0.78,0.96)$ & $0.85(0.80,0.92)$ & 0.02 \\
\hline Final model ${ }^{\mathrm{e}}$ : & 1 & $0.88(0.79,0.98)$ & $0.85(0.81,0.94)$ & 0.02 \\
\hline \multicolumn{5}{|c|}{ Age at menarche $(n=1752)$} \\
\hline Unadjusted model: & 1 & $0.91(0.83,0.98)$ & $0.88(0.81,0.94)$ & 0.03 \\
\hline Model 2d: & 1 & $0.89(0.81,0.97)$ & $0.87(0.79,0.95)$ & 0.02 \\
\hline \multirow[t]{2}{*}{ Final model ${ }^{\mathrm{e}}$ : } & 1 & $0.89(0.80,0.97)$ & $0.86(0.80,0.95)$ & 0.02 \\
\hline & Lower $(46.1-77.5)^{\mathrm{f}}$ & Moderate $(78.2-101.7)^{\mathrm{f}}$ & Higher $(102.3-131.5)^{\mathrm{f}}$ & $p_{\text {trend }}{ }^{\mathrm{c}}$ \\
\hline \multicolumn{5}{|l|}{ Boys } \\
\hline \multicolumn{5}{|c|}{ Age at Tanner stage G2 $(n=2231)$} \\
\hline Unadjusted model: & 1 & $0.92(0.84,1.02)$ & $0.87(0.78,0.95)$ & 0.03 \\
\hline Model 2d: & 1 & $0.90(0.82,0.98)$ & $0.86(0.79,0.96)$ & 0.02 \\
\hline Final model ${ }^{\mathrm{e}}$ : & 1 & $0.89(0.82,0.97)$ & $0.86(0.80,0.96)$ & 0.02 \\
\hline \multicolumn{5}{|c|}{ Age at voice break $(n=2231)$} \\
\hline Unadjusted model: & 1 & $0.93(0.86,1.05)$ & $0.85(0.74,1.04)$ & 0.05 \\
\hline Model $2^{\mathrm{d}}$ : & 1 & $0.91(0.85,1.01)$ & $0.86(0.76,0.97)$ & 0.04 \\
\hline Final model ${ }^{\mathrm{e}}$ : & 1 & $0.90(0.83,0.98)$ & $0.86(0.79,0.98)$ & 0.03 \\
\hline
\end{tabular}

${ }^{a}$ Values are models adjusted hazard ratios $(95 \% \mathrm{CI}), H R=$ hazard ratio; diet quality was assessed according to CCDI (Chinese Children Dietary Index) based on diet data at baseline

${ }^{\mathrm{b}}$ Values are min-max in tertiles in girls

${ }^{\mathrm{c}} P$ for trend across CCDI tertiles were performed by including CCDI ordinals as continuous variables

${ }^{\mathrm{d}}$ Adjusted for paternal education level and energy intake at baseline

${ }^{\mathrm{e}}$ Additionally adjusted for percent body fat at baseline

${ }^{\mathrm{f}}$ Values are min-max in tertiles in boys

to adjust for a number of major potential confounders both in children and in their parents were the considerable strengths. Moreover, our participants and their parents/family were representative of the general population in age, economic and education status according to the regional statistic books [50-52].

Some limitations of our study should be mentioned. Firstly, in contrast to factor analysis and cluster analysis, which are commonly used for dietary pattern analysis [27], the dietary indices typically summarize scores of the degree to which an individual's diet conforms to specific dietary recommendations, i.e., dietary index is an "a priori" defined dietary pattern created on the basis of previous knowledge. Dietary indices can thus be fraught with uncertainties in selecting components to assign a score and subjectivity in defining cut-off points. In our analysis, all of the current dietary recommendations, on which CCDI constructed, were not especially relevant to puberty timing. Furthermore, dietary index does not consider the correlation structure of foods and nutrient intakes. It might be more applicable to 
focus on the variation in such nutrients, foods and eating behaviors that presumably affect the puberty timing. Finally, data deriving from a FFQ may not be representative of habitual dietary intake. However, our sensitivity analyses showed similar associations between diet quality deriving from 24-h recalls and puberty timing, which has partly overcome this potential limitation.

In conclusion, our data suggested that children with higher diet quality in prepuberty entered their puberty at a later age. This association was independent of pre-pubertal body fat.

Acknowledgements The participation of all children and their families is gratefully acknowledged. The authors also thank the staff of the Healthy Food Evaluation Research Center for carrying out the interview, anthropometric measurements and pubertal development examinations.

Author contributions G.C. conceived the project. R.D. and G.C. performed the analyses and wrote the manuscript. R.D. and T.Q. performed the initial data analyses. L.Z., Y.C., T.Q., M.C., H.X, X.Z., M.Y. and Y.L. coordinated the study centers. G.C. supervised the study. All authors critically reviewed the manuscript for important intellectual content.

Funding This work was supported by a research grant from the New Century Excellent Talents in University Program (NCET-12-0377), Sichuan Outstanding Young Scholars Foundation (2014JQ0005) and the National Natural Science Foundation of China (81673158).

Code availability Not applicable.

\section{Compliance with ethical standards}

Conflict of interest The authors have no conflicts of interest to disclose. The interpretation and reporting of these data are the sole responsibility of the authors.

Ethics approval The study was approved by the Ethics Committee of the Sichuan University.

Consent to participant All examinations and questionnaires were performed with parental consent.

Consent for publication Not applicable.

Availability of data and material The datasets used and/or analyzed during the current study are available from the corresponding author on reasonable request.

Open Access This article is licensed under a Creative Commons Attribution 4.0 International License, which permits use, sharing, adaptation, distribution and reproduction in any medium or format, as long as you give appropriate credit to the original author(s) and the source, provide a link to the Creative Commons licence, and indicate if changes were made. The images or other third party material in this article are included in the article's Creative Commons licence, unless indicated otherwise in a credit line to the material. If material is not included in the article's Creative Commons licence and your intended use is not permitted by statutory regulation or exceeds the permitted use, you will need to obtain permission directly from the copyright holder. To view a copy of this licence, visit http://creativecommons.org/licenses/by/4.0/.

\section{References}

1. Cancer CGoHFiB, (2012) Menarche, menopause, and breast cancer risk: individual participant meta-analysis, including 118 964 women with breast cancer from 117 epidemiological studies. Lancet Oncol 13(11):1141-1151. https://doi.org/10.1016/s1470 $-2045(12) 70425-4$

2. Gong TT, Wu QJ, Vogtmann E, Lin B, Wang YL (2013) Age at menarche and risk of ovarian cancer: a meta-analysis of epidemiological studies. Int J Cancer 132(12):2894-2900. https:// doi.org/10.1002/ijc.27952

3. Gong TT, Wang YL, Ma XX (2015) Age at menarche and endometrial cancer risk: a dose-response meta-analysis of prospective studies. Sci Rep 5:14051. https://doi.org/10.1038/srep1 4051

4. Nair-Shalliker V, Yap S, Nunez C, Egger S, Rodger J, Patel MI, O'Connell DL, Sitas F, Armstrong BK, Smith DP (2017) Adult body size, sexual history and adolescent sexual development, may predict risk of developing prostate cancer: results from the New South Wales lifestyle and evaluation of risk study (CLEAR). Int J Cancer 140(3):565-574. https://doi.org/10.1002/ijc.30471

5. Sarre S, Määttänen L, Tammela TLJ, Auvinen A, Murtola TJ (2016) Postscreening follow-up of the finnish prostate cancer screening trial on putative prostate cancer risk factors: vitamin and mineral use, male pattern baldness, pubertal development and non-steroidal anti-inflammatory drug use. Scand J Urol 50(4):267-273. https://doi.org/10.3109/21681805.2016.1145734

6. Garner MJ, Turner MC, Ghadirian P, Krewski D (2005) Epidemiology of testicular cancer: an overview. Internat J Cancer 116(3):331-339

7. Chen X, Liu Y, Sun X, Yin Z, Li H, Liu X, Zhang D, Cheng C, Liu L, Liu F, Zhou Q, Wang C, Li L, Wang B, Zhao Y, Liu D, Zhang M, Hu D (2018) Age at menarche and risk of all-cause and cardiovascular mortality: a systematic review and dose-response metaanalysis. Menopause 26(6):670-676. https://doi.org/10.1097/ GME.0000000000001289

8. Frontini MG, Srinivasan SR, Berenson GS (2003) Longitudinal changes in risk variables underlying metabolic syndrome $\mathrm{X}$ from childhood to young adulthood in female subjects with a history of early menarche: the bogalusa heart study. Int J Obes Relat Metab Disord 27(11):1398-1404. https://doi.org/10.1038/sj.ijo.0802422

9. Freedman DS, Khan LK, Serdula MK, Dietz WH, Srinivasan SR, Berenson GS, Hearts B (2003) The relation of menarcheal age to obesity in childhood and adulthood: the Bogalusa heart study. BMC Pediatr 3:3-3. https://doi.org/10.1186/1471-2431-3-3

10. Günther ALB, Karaolis-Danckert N, Kroke A, Remer T, Buyken AE (2010) Dietary protein intake throughout childhood is associated with the timing of puberty. J Nutr 140(3):565-571. https:// doi.org/10.3945/jn.109.114934

11. Jansen EC, Marín C, Mora-Plazas M, Villamor E (2015) Higher childhood red meat intake frequency is associated with earlier age at menarche. J Nutr 146(4):792-798. https://doi.org/10.3945/ jn. 115.226456

12. Rogers IS, Northstone K, Dunger DB, Cooper AR, Ness AR, Emmett PM (2010) Diet throughout childhood and age at menarche in a contemporary cohort of British girls. Public Health Nutr 13(12):2052-2063. https://doi.org/10.1017/S136898001 0001461

13. Günther ALB, Stahl LJ, Buyken AE, Kroke A (2011) Association of dietary energy density in childhood with age and body fatness 
at the onset of the pubertal growth spurt. Br J Nutr 106(3):345349. https://doi.org/10.1017/S0007114511001772

14. Kwok MK, Leung GM, Lam TH, Schooling CM (2012) Breastfeeding, childhood milk consumption, and onset of puberty. Pediatrics 130(3):e631-e639. https://doi.org/10.1542/peds.2011-3697

15. Carwile JL, Willett WC, Wang M, Rich-Edwards J, Frazier AL, Michels KB (2015) Milk consumption after age 9 years does not predict age at menarche. J Nutr 145(8):1900-1908. https://doi. org/10.3945/jn.115.214270

16. Meng X, Li S, Duan W, Sun Y, Jia C (2017) Secular trend of age at menarche in Chinese adolescents born from 1973 to 2004. Pediatrics 140(2):e20170085. https://doi.org/10.1542/peds.2017-0085

17. Ramezani Tehrani F, Moslehi N, Asghari G, Gholami R, Mirmiran P, Azizi F (2013) Intake of dairy products, calcium, magnesium, and phosphorus in childhood and age at menarche in the Tehran Lipid and Glucose Study. PLoS ONE 8(2):e57696-e57696. https ://doi.org/10.1371/journal.pone.0057696

18. Schraw JM, Øgland B, Dong YQ, Nilsen ST, Forman MR (2015) In utero preeclampsia exposure, milk intake and pubertal development. Reprod Toxicol 54:19-25. https://doi.org/10.1016/j.repro tox.2014.12.004

19. Carwile JL, Willett WC, Spiegelman D, Hertzmark E, RichEdwards J, Frazier AL, Michels KB (2015) Sugar-sweetened beverage consumption and age at menarche in a prospective study of US girls. Hum Reprod 30(3):675-683. https://doi.org/10.1093/ humrep/deu349

20. Mueller NT, Jacobs DR, MacLehose RF, Demerath EW, Kelly SP, Dreyfus JG, Pereira MA (2015) Consumption of caffeinated and artificially sweetened soft drinks is associated with risk of early menarche. Am J Clin Nutr 114:100958

21. Cheng HL, Raubenheimer D, Steinbeck K, Baur L, Garnett S (2019) New insights into the association of mid-childhood macronutrient intake to pubertal development in adolescence using nutritional geometry. Br J Nutr 122(3):274-283. https://doi. org/10.1017/S0007114519001326

22. Koo MM, Rohan TE, Jain M, McLaughlin JR, Corey PN (2002) A cohort study of dietary fibre intake and menarche. Public Health Nutr 5(2):353-360. https://doi.org/10.1079/PHN2002261

23. Cheng G, Remer T, Prinz-Langenohl R, Blaszkewicz M, Degen GH, Buyken AE (2010) Relation of isoflavones and fiber intake in childhood to the timing of puberty. Am J Clin Nutr 92(3):556564. https://doi.org/10.3945/ajen.2010.29394

24. Gaskins AJ, Pereira A, Quintiliano D, Shepherd JA, Uauy R, Corvalán C, Michels KB (2017) Dairy intake in relation to breast and pubertal development in Chilean girls. Am J Clin Nutr 105(5):1166-1175. https://doi.org/10.3945/ajen.116.150359

25. Ma HM, Chen SK, Chen RM, Zhu C, Xiong F, Li T, Wang W, Liu GL, Luo XP, Liu L, Du ML, Pubertal Study Group of the Society of Pediatric E, Genetic Disease CMA (2011) Pubertal development timing in urban Chinese boys. Int J Androl 34(5 Pt 2):e435-e445. https://doi.org/10.1111/j.1365-2605.2011.01173.x

26. Ma H-M, Du M-L, Luo X-P, Chen S-K, Liu L, Chen R-M, Zhu C, Xiong F, Li T, Wang W, Liu G-L, Pubertal Study Group of the Society of Pediatric E, Genetic Disease CMA (2009) Onset of breast and pubic hair development and menses in urban Chinese girls. Pediatrics 124(2):e269-e277. https://doi.org/10.1542/ peds.2008-2638

27. Hu FB (2002) Dietary pattern analysis: a new direction in nutritional epidemiology. Curr Opin Lipidol 13(1):3-9. https://doi. org/10.1097/00041433-200202000-00002

28. Szamreta EA, Qin B, Rivera-Núñez Z, Parekh N, Barrett ES, Ferrante J, Lin Y, Bandera EV (2019) Greater adherence to a Mediterranean-like diet is associated with later breast development and menarche in peripubertal girls. Public Health Nutr 1:11. https://doi.org/10.1017/S1368980019002349
29. Cheng G, Gerlach S, Libuda L, Kranz S, Günther ALB, KaraolisDanckert N, Kroke A, Buyken AE (2010) Diet quality in childhood is prospectively associated with the timing of puberty but not with body composition at puberty onset. J Nutr 140(1):95-102. https://doi.org/10.3945/jn.109.113365

30. Cheng G, Duan R, Kranz S, Libuda L, Zhang L (2016) Development of a dietary index to assess overall diet quality for Chinese school-aged children: the Chinese children dietary index. J Acad Nutr Diet 116(4):608-617. https://doi.org/10.1016/j. jand.2015.11.010

31. Society CN (2016) Dietary guidelines for Chinese. People's Medical Publishing House, Beijing, China

32. Wagner IV, Sabin MA, Pfäffle RW, Hiemisch A, Sergeyev E, Körner A, Kiess W (2012) Effects of obesity on human sexual development. Nat Rev Endocrinol 8(4):246-254. https://doi. org/10.1038/nrendo.2011.241

33. Jia P, Xue H, Zhang J, Wang Y (2017) Time trend and demographic and geographic disparities in childhood obesity prevalence in China-evidence from twenty years of longitudinal data. Int J Environ Res Public Health 14(4):369. https://doi. org/10.3390/ijerph14040369

34. Yang MZ, Xue HM, Pan J, Libuda L, Muckelbauer R, Yang M, Quan L, Cheng G (2018) High protein intake along with paternal part-time employment is associated with higher body fat mass among girls from South China. Eur J Nutr 57(5):1845-1854. https ://doi.org/10.1007/s00394-017-1468-1

35. Black AE (2000) Critical evaluation of energy intake using the Goldberg cut-off for energy intake: basal metabolic rate A practical guide to its calculation, use and limitations. Int J Obes Relat Metab Disord 24(9):1119-1130. https://doi.org/10.1038/ sj.ijo.0801376

36. Duan R, Liu Y, Xue H, Yang M, Cheng G (2014) Cross-sectional association between overall diet quality and overweight/obesity among children and adolescents in Chengdu. Zhonghua liu xing bing xue za zhi Zhonghua liuxingbingxue zazhi 35(9):994-998

37. Society CN (2007) Chinese dietary guidelines. Tibet people's Publishing House, Lhasa

38. Society CN (2014) Dietary reference intakes for Chinese (Version 2013). Science Press, Beijing

39. Qiao T, Duan R, Cheng G (2019) Revision of the Chinese children dietary index. Acta Nutrimenta Sinica 41(2):105-109

40. Marshall WA, JM T (1986) Puberty A comprehensive treatise. In: Falkner F, JM T (eds) Human Growth: a comprehensive treatise. Plenum Press, New York

41. Li H, Ji CY, Zong XN, Zhang YQ (2009) Body mass index growth curves for Chinese children and adolescents aged 0 to 18 years. Zhonghua er ke za zhi Chinese J Pediatr 47(7):493-498

42. Cole TJ, Bellizzi MC, Flegal KM, Dietz WH (2000) Establishing a standard definition for child overweight and obesity worldwide: international survey. BMJ 320(7244):1240-1243. https://doi. org/10.1136/bmj.320.7244.1240

43. Slaughter MH, Lohman TG, Boileau RA, Horswill CA, Stillman RJ, Van Loan MD, Bemben DA (1988) Skinfold equations for estimation of body fatness in children and youth. Hum Biol 60(5):709-723

44. Kaplowitz PB (2008) Link between body fat and the timing of puberty. Pediatrics 121(Suppl 3):S208-217. https://doi. org/10.1542/peds.2007-1813F

45. Carruba G, Granata OM, Pala V, Campisi I, Agostara B, Cusimano R, Ravazzolo B, Traina A (2006) A traditional Mediterranean diet decreases endogenous estrogens in healthy postmenopausal women. Nutr Cancer 56(2):253-259. https://doi.org/10.1207/ s15327914nc5602_18

46. Pereira MA (2013) Diet beverages and the risk of obesity, diabetes, and cardiovascular disease: a review of the evidence. Nutr Rev 71(7):433-440. https://doi.org/10.1111/nure.12038 
47. van Jaarsveld CHM, Fidler JA, Simon AE, Wardle J (2007) Persistent impact of pubertal timing on trends in smoking, food choice, activity, and stress in adolescence. Psychosom Med 69(8):798806. https://doi.org/10.1097/PSY.0b013e3181576106

48. Goldin BR, Woods MN, Spiegelman DL, Longcope C, MorrillLaBrode A, Dwyer JT, Gualtieri LJ, Hertzmark E, Gorbach SL (1994) The effect of dietary fat and fiber on serum estrogen concentrations in premenopausal women under controlled dietary conditions. Cancer 74(3 Suppl):1125-1131. https://doi. org/10.1002/1097-0142(19940801)74:3+\%3c1125::aid-cncr2 820741521\%3e3.0.co;2-5

49. Aeberli I, Molinari L, Spinas G, Lehmann R, Allemand D, Zimmermann MB (2006) Dietary intakes of fat and antioxidant vitamins are predictors of subclinical inflammation in overweight Swiss children. Am J Clin Nutr 84(4):748-755. https://doi. org/10.1093/ajcn/84.4.748
50. Guizhou S (2013) Guizhou statistical yearbook. China Statistic Press, Beijing

51. Sichuan S (2013) Sichuan statistical yearbook. China Statistic Press, Beijing

52. Yunnan S (2013) Yunnan statistical yearbook. China Statistic Press, Beijing

53. VanItallie TB, Yang MU, Heymsfield SB, Funk RC, Boileau RA (1990) Height-normalized indices of the body's fat-free mass and fat mass: potentially useful indicators of nutritional status. Am J Clin Nutr 52(6):953-959. https://doi.org/10.1093/ajen/52.6.953

54. Guenther PM, Casavale KO, Reedy J, Kirkpatrick SI, Hiza HA, Kuczynski KJ, Kahle LL, Krebs-Smith SM (2013) Update of the healthy eating index: HEI-2010. J Acad Nutr Diet 113(4):569580. https://doi.org/10.1016/j.jand.2012.12.016

\section{Affiliations}

\section{Ruonan Duan ${ }^{1} \cdot$ Tian Qiao $^{1} \cdot$ Yue Chen ${ }^{1} \cdot$ Mengxue Chen $^{1} \cdot$ Hongmei Xue ${ }^{1,2} \cdot$ Xue Zhou $^{1,3,4} \cdot$ Mingzhe Yang $^{1,5}$.

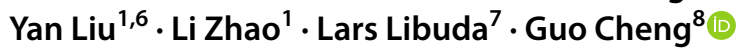

1 West China School of Public Health and West China Fourth Hospital and Healthy Food Evaluation Research Center, Sichuan University, Chengdu, People's Republic of China

2 College of Public Health, Hebei University, Baoding, People's Republic of China

3 Department of Clinical Nutrition, Sichuan Academy of Medical Sciences and Sichuan Provincial People's Hospital, Chengdu, People's Republic of China

4 Chinese Academy of Sciences Sichuan Translational Medicine Research Hospital, Chengdu, People's Republic of China

5 Nutrition and Health Research Centre, By-Health Co. Ltd, No. 3 Kehui 3rd Street, No. 99 Kexue Avenue Central, Science City, Huangpu District, Guangzhou, People's Republic of China
6 Department of Clinical Nutrition, Chengdu First People's Hospital, Chengdu, People's Republic of China

7 Department of Child and Adolescent Psychiatry, University Hospital Essen, University of Duisburg-Essen, Essen, Germany

8 Laboratory of Molecular Translational Medicine, Center for Translational Medicine, Key Laboratory of Birth Defects and Related Diseases of Women and Children (Sichuan University), Ministry of Education, Department of Pediatrics, West China Second University Hospital, Sichuan University, Chengdu, Sichuan 610041, People's Republic of China 